\title{
FURTHER EXPERIMENTAL PRODUCTION OF CURRENCY PAPER IN THE BUREAU OF STANDARDS PAPER MILL ${ }^{1}$
}

\author{
By Merle B. Shaw and George W. Bicking
}

\section{ABSTRACT}

The work continues the investigation to improve the durability of United States currency paper previously reported in Technologic Paper No. 329. The wear-resistant quality of currency paper was very much increased as a result of the experimental tests described in the earlier publication, but additional study of the paper-manufacturing processes with a view to further prolonging the service life of the currency was subsequently requested. The research was conducted in cooperation with the Bureau of Efficiency and the Bureau of Engraving and Printing.

The study included the use of caustic soda as compared with lime for cooking the rags, the effect of variation in the fiber composition of the paper, the effect of modifications in the beating process, determination of optimum surface-sizing conditions for best printing results, and printing tests on the finished experimental papers.

The data showed that either lime or caustic soda is satisfactory as the digesting agent in the cooking process. Fiber mixtures of 75 per cent linen and 25 per cent cotton gave the best paper for currency use, although paper made from equal proportions of these fibers was of very good quality. Gradual application of roll pressure in the beating process was found to be essential to best results. Formaldehyde proved better than alum as glue preservative in the surface-sizing bath.

Comparative tests of commercial manufacturing procedure and bureau practice were made at the request of manufacturers desiring to produce paper of the type developed in the investigation. The experimental procedure gave equally good results with commercial equipment, and paper of similar quality is now being made commercially.

Description of the manufacturing procedure, tables of experimental data, and discussion of the results are included in the publication.

\section{CONTENTS}

I. Introduction and résumé of previous work

II. Paper-making fiber used.

III. Paper-making equipment

IV. Preparation of the half stuff.

1. Cleaning and cutting

- - - - - - - - - - - - - - - - - - - - -

2. Cooking

3. Washing-_._.

4. Bleaching

5. Loss of fiber

1 Supplemental to B. S. Tech. Paper No. 329. 
V. Paper-making processes

1. Beating .

2. Paper-machine operation

3. Glue surface sizing

VI. Test data on finished unsized paper

1. Stock prepared from lime-cooked rags

(a) $75: 25$ linen-cotton mixture

(b) $50: 50$ linen-cotton mixture

(c) $25: 75$ linen-cotton mixture

(d) 100 per cent cotton

2. Stock prepared from rags cooked with caustic soda

(a) $75: 25$ linen-cotton mixture

(b) $50: 50$ linen-cotton mixture

(c) 100 per cent cotton

VII. Paper-making tests in cooperation with commercial mills

1. Mill A

2. Mill B

3. Mill $\mathrm{C}$

\section{INTRODUCTION AND RÉSUME OF PREVIOUS WORK}

Results of research on the production of currency paper in the Bureau of Standards experimental paper mill were published previously in Technologic Paper No. 329, ${ }^{2}$ issued October, 1926. The present publication relates to a continuation of the study and is supplementary to the earlier work.

The previous publication dealt with various proportions of linen and cotton paper-making fibers and a study of the paper-making processes. Lime was the cooking chemical employed in the pulping operation. Conclusions as to the fiber composition and the papermaking procedure found to yield the most satisfactory paper were included in the publication.

The paper produced in the experimental tests was of good printing quality and of much greater strength than that in use when the investigation was initiated. The experimental procedure was applied in commercial production with such satisfactory results that the Treasury Department consequently revised the contract specifications. Currency paper of more than double the strength previously specified was subsequently delivered, without increase in cost to the Government or to the manufacturing contractor. Statistics of the Treasury Department show that as a result of the research the average service life of paper currency was increased about 40 per cent.

The principal factor in the improvement of the durability of the paper was the manner and duration of the beating treatment accorded the fibers in the manufacturing process. Full details of the beating

2 Publication may be obtained from the Superintendent of Documents, Government Printing Office, Washington, D. C. Price, 10 cents. 
procedure developed and recommended were included in Technologic Paper No. 329.

There seems to have been no demand previously for commercial paper of such high fiber strength as that made experimentally at the bureau in the investigation. Since the completion of the work described in the earlier publication, however, a number of fine-paper manufacturers have become interested in its production and have cooperated with the bureau in the later investigative work to develop this type of paper for various commercial uses. The results reported in this and in the previous paper are considered, therefore, to be of value in the manufacture of fine rag papers in general, as the processes developed appear to be applicable to several types of commercial papers, particularly bonds and ledgers.

The present report gives the results of comparative study of commercial manufacturing operations and bureau practice; further experimental study of the beating procedure with the fiber mixture specified for currency paper; the use of other combinations of these fibers; the use of caustic soda, as compared with lime, for cooking the rags; and tests to establish the best procedure for surface-sizing the paper-machine product.

Since the methods and theoretical considerations were, to a large extent, the same as those described in the preceding publication, the present article will be limited, in general, to the essential respects in which the work deviated from that described before, and to a statement of the results obtained.

\section{PAPER-MAKING FIBER USED}

It was not considered expedient when starting the investigation to outline the complete program, and, consequently, the raw materials were not all purchased at one time. Those secured for the present tests, however, duplicated as nearly as possible the earlier purchases and, like those, also were obtained from the stock used by a manufacturer of the Government currency paper. The materials consisted of new rags graded as white and cream linen cuttings, brown and gray linen cuttings, white cotton shirt cuttings, and cream cotton hosiery clippings. The composition of the beater "furnish" - that is, the various paper-making materials blended in the beater-is included in the description of each paper-machine run.

\section{PAPER-MAKING EQUIPMENT}

The paper mill of the bureau is equipped for making paper on a semicommercial scale under practical mill conditions. The equipment employed in the manufacture of experimental currency paper was that in general use in the mill and consisted of a rag duster; rag 
cutter; rotary boiler; 50 -pound copper-lined wood-tub beater, having manganese-bronze bars and plate and equipped with a washing cylinder; 300-pound tile-lined cement beater, having phosphorbronze bars and plate and equipped with two washing cylinders; small Jordan refiner with iron bars; a 4-plate screen; a 29-inch Fourdrinier paper-making machine, with wire 33 feet long and having two presses, nine 15-inch dryers, a small machine stack of seven rolls, and a reel; a surface-sizing bath and drying cabinet; and a 5-roll supercalender.

Photographs of the duster, cutter, rotary boiler, 50-pound beater, Jordan, and Fourdrinier machine are shown in B. S. Technologic Paper No. 340, Caroá Fiber as a Paper-Making Material, pages 338 to 341 . Photographs of the surface-sizing equipment follow herein.

\section{PREPARATION OF THE HALF STUFF}

The procedure followed in the preparation of the half stuff was essentially the same as that generally observed in the commercial production of high-grade papers.

\section{CLEANING AND CUTTING}

Since the rags employed in the tests were new and already graded as to material and color (uniform in quality), only dusting, cutting, and subsequently dusting again were necessary to prepare the material for the digestion process. In the cutting operation the rags were reduced to pieces averaging less than 10 square inches in area.

\section{COOKING}

The cooking process, which dissolves the noncellulose material and softens the paper-making fiber, thereby permitting it to respond more readily to the subsequent treatment, freed the rags from such impurities as dyes, size, starch, dirt, grease, or other incrusting materials. In the work previously reported lime was used in the boiling solutions, but in the tests described in this paper caustic soda and lime each served as a solvent to effect the chemical cleansing.

The constant factors for each cook, whether lime or caustic soda was used, were as follows:

Weight of bone-dry fiber....

Volume of water.

Initial temperature $\circ \mathrm{F} .$. $70-80$

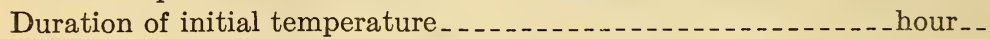

Time for raising to cooking temperature . .

Cooking temperature $\circ F_{--} 250-260$

Duration of cooking temperature ... 
Unless otherwise stated the white and cream linens were kept separate from the gray and brown in cooking, and the cotton rags were cooked alone. The few departures from this procedure are specifically noted in the description of the corresponding papermachine run.

The strength of the cooking liquor was varied according to the kind of rags being treated. In the case of lime cooks, 6 per cent of lime, based on the weight of the rags, was used for the cotton and the white and cream linens; 12 per cent for the colored linens. For the soda process 2 per cent of commercial caustic soda (96 per cent sodium. hydroxide) was employed for the cotton rags (light-colored); 4 per cent for the light-colored linens; and 5 per cent for the dark-colored linens. In the few cases in which light and dark linens were cooked together, 4 per cent of caustic soda was used when the mixture was 25 per cent cotton and 75 per cent linen; 3 per cent when 50 per cent cotton and 50 per cent linen. The amounts of caustic used were not predetermined by experimental tests but were selected on judgment. They proved very satisfactory, however, and, as shown by the tests, were very close to the quantities required.

In preparing the lime solution a small amount of the water was used for slaking, and the remainder of the 52.5 gallons was later added to and thoroughly mixed with the slaked lime. The mixture was run into the boiler through a 60 -mesh screen to remove sand, splinters of wood, coal particles, or other objectionable material. The caustic soda was dissolved in the water, which was equal in volume to that used for the lime cook, and the solution likewise screened as it was charged into the boiler.

\section{WASHING}

The cooked rags were transferred to the 50-pound beater and washed until the effluent was clear, to remove the cooking liquor and the loosened impurities. One-half of a cook constituted a charge. The time required for washing was about two and one-half hours. The amount of water used was 1,500 gallons, or 30 gallons per pound of rags, for each complete operation.

The beating action was continued further to brush the fibers out of weave. The cotton and uncolored linens responded somewhat more readily to this treatment than the gray or brown linens. The former materials required from $6 \frac{1}{2}$ to 7 hours, and the latter, 7 to $7 \frac{1}{2}$ hours, for conversion into the partially prepared pulp, commonly termed "half stuff."

\section{BLEACHING}

A solution of calcium hypochlorite, from bleaching powder, was mixed with the half stuff, which was then dropped into a drainer where the liquor was allowed to drain off and the residual bleach to become spent. The procedure followed was, in general, the same as that 
described in Technologic Paper No. 329, pages 95 and 96. Any deviation therefrom is noted in the description of the corresponding paper-machine run.

\section{LOSS OF FIBER}

The loss of fiber sustained in converting the rags to half stuff was determined for a few of the cooks by the caustic-soda process.

The total loss in cooking, washing, and bleaching mixtures of 75 per cent linen and 25 per cent cotton rags, cooked together, with 4 per cent of caustic soda, was from 15 to 19 per cent. The determination was made for each of three cooks. For a boiler furnish of 50 per cent linen and 50 per cent cotton, cooked with 3 per cent of caustic, the total loss was 13.75 per cent. For 100 per cent cotton, cooked with 2 per cent of caustic soda, the total loss was 7 per cent, but in the case of 100 per cent linen, cooked with 4 per cent of caustic soda, the loss was 21 per cent.

\section{PAPER-MAKING PROCESSES}

\section{BEATING}

The beating was conducted in the same manner as described in Technologic Paper No. 329. The characteristic feature of the method of beating used at the bureau in the production of experimental currency paper is the very gradual lowering of the beater roll.

Before the furnish was added to the beater the roll was raised off the plate, by turning the handwheel, in order to give clearance to the lumps of half stuff. The tub was partially filled with water, half stuff from the drainers was introduced, and additional water was run in until the desired concentration was obtained. After sufficient circulation of the furnish the roll was gradually lowered on the plate, by definite amounts and at fixed intervals, to brush out the fibers and reduce them to optimum length.

Measurements were made indicating the relative rate at which water drained from the stuff. Since the fibers differed by nature, however, in physical characteristics and resultant susceptibility to the hydrating influence of the beating action, the beating was controlled by manipulation of the roll, and was independent of the results of the freeness tests. The duration of the beating and the observed freeness readings are recorded for the machine runs in Table 1.

For further details of beater manipulation and discussion of the factors affecting the freeness of the beaten pulp, and the consequent characteristics of finished paper, the reader is referred to the earlier publication, pages 96 to 102 . Description of the apparatus and method used in measuring the freeness of the stuff are also included. 


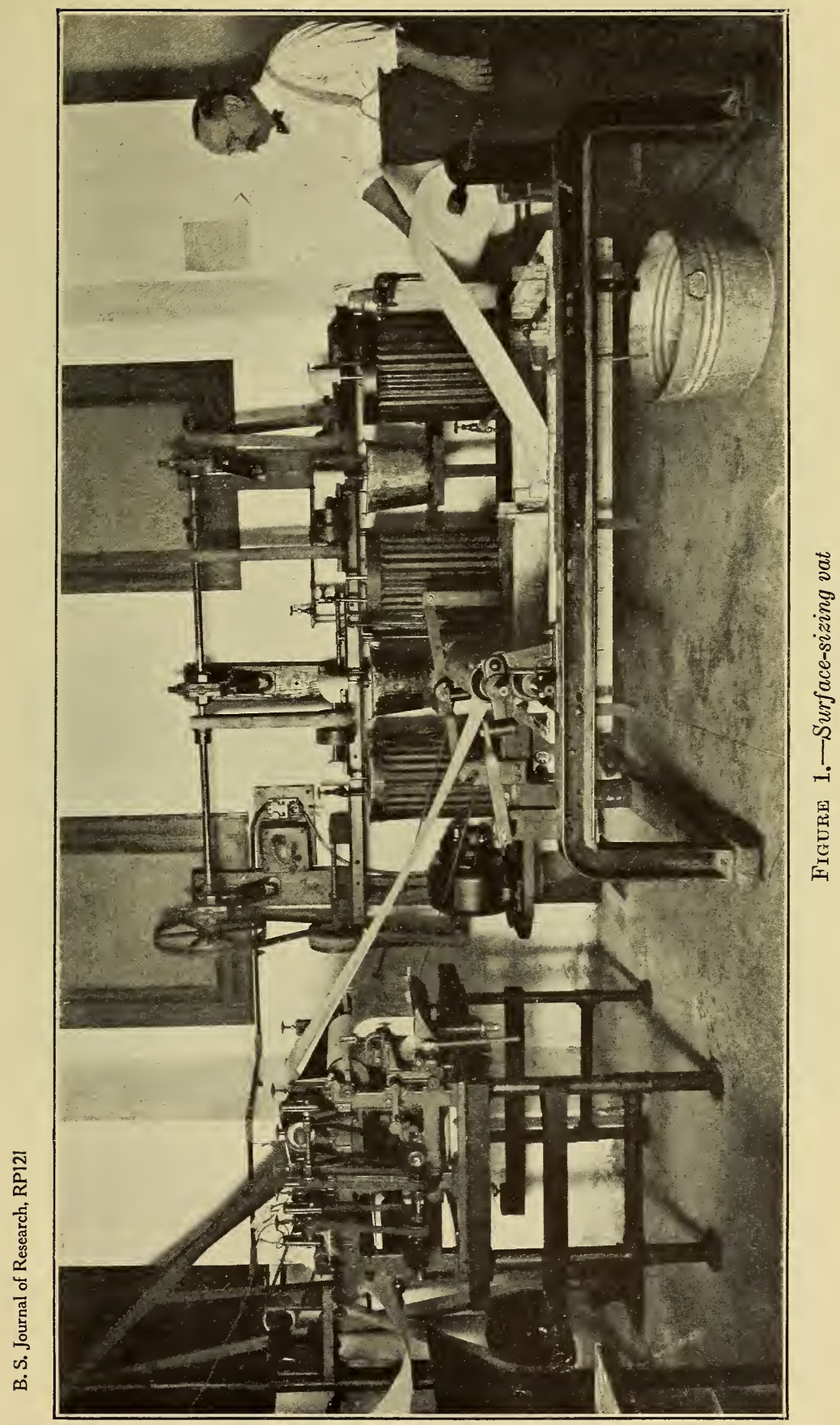


B. S. Journal of Research, RP121

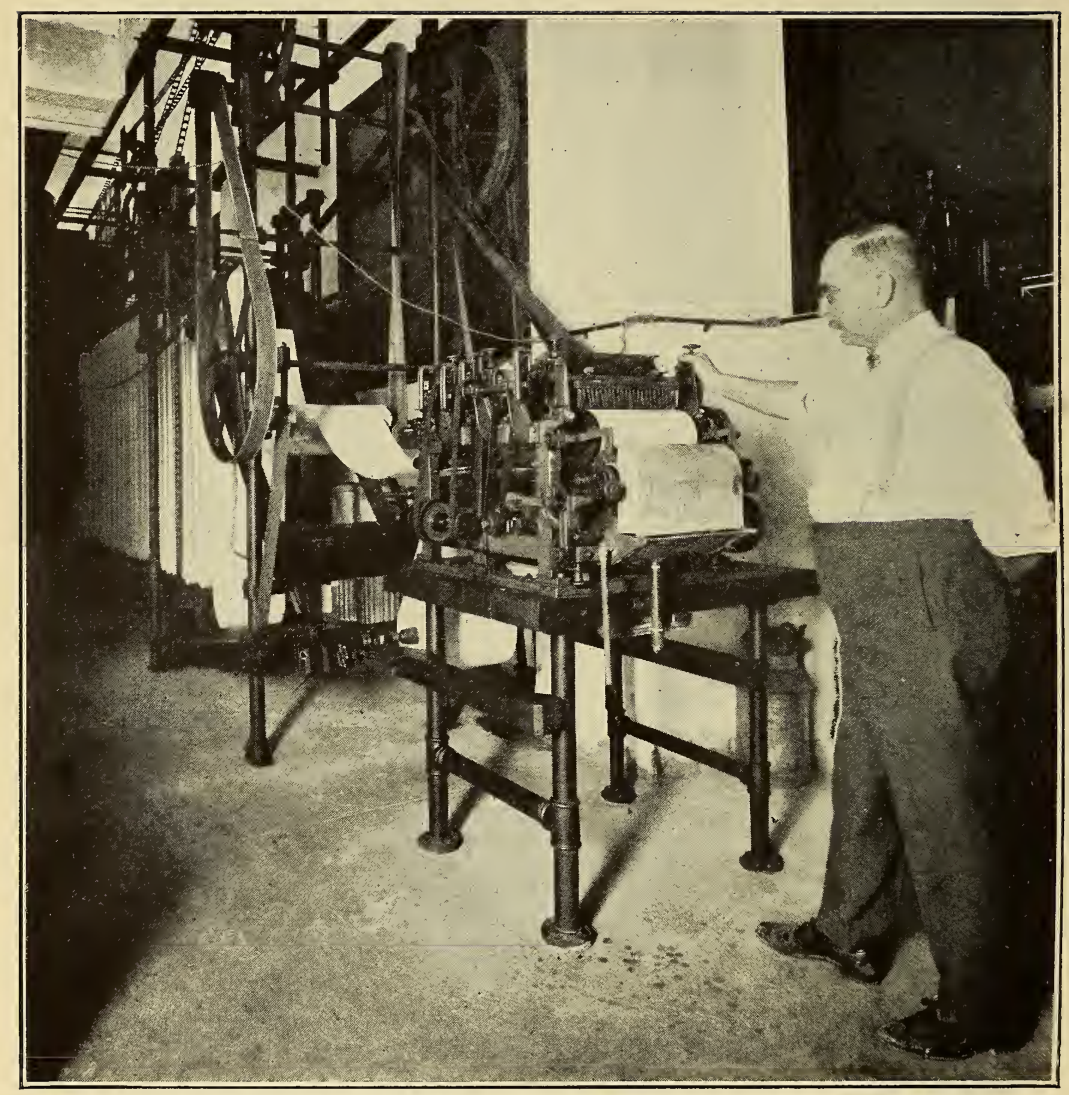

FIgURe 2.-Festoon rack

(Coating machine in foreground not used in currency tests.) 


\section{PAPER-MACHINE OPERATION}

From the stuff chest the beaten half stuff was pumped in a continuous stream through the stuff box and the Jordan refiner, and thence to the paper machine. Pumping the stock from the Jordan directly to the paper machine is considered better practice than discharging it into a machine chest and subsequently withdrawing it as needed. By the former method changes in the character of the stock indicated as desirable by conditions at the screen, on the paper machine, or in the finished sheet can be effected rapidly by suitable adjustments of the Jordan.

The operation of the paper machine was very carefully controlled during the tests. For additional details of the operation see Technologic Paper No. 329, pages 102-103.

\section{GLUE SURFACE SIZING}

Some of the papers were surface sized for experimental printing tests. The waterleaf or unsized paper thus treated was run through a heated solution of animal glue, passed between a pair of squeeze rolls which removed the excess size, and hung in festoons to dry. The final operation consisted in passing the dried paper through the supercalender to give it the desired finish.

Figures 1 and 2 show the surface-sizing equipment. The vat for the sizing solution is an open wooden box, $58 \frac{1}{2}$ by 24 by 8 inches. It is heated by a steam coil of three-fourths inch galvanized-iron pipe 20 feet in length, and contains three adjustable rolls for regulating the degree of immersion of the paper in the bath. The squeeze rolls are 5 inches in diameter. The upper roll is brass and the lower one has a rubber covering on a steel core. The festoon rack is 15 feet long and has a capacity of 28 loops, each 6 feet in length. With the uptake rack and the rack from the festoons to the reel, the capacity of the dryer is 400 feet. The dryer is inclosed in a cabinet equipped for air conditioning and temperature control. The view shows the festoon system without the cabinet.

The sizing solutions employed in the tests contained from 1 to 6 per cent of glue, and alum or formaldehyde added as a preservative. The temperature ranged from $120^{\circ}$ to $140^{\circ} \mathrm{F}$. Description of the tests is included in the section, Glue Surface-Sizing Tests, following.

\section{TEST DATA ON FINISHED UNSIZED PAPER}

Table 1 gives data relative to the furnish and the operation of the beater for each machine run, and various measurements on the finished waterleaf or unsized paper. The apparatus and methods em- 
ployed in making the measurements, with the exception of copper number, are fully described in Paper Testing Methods, published by the Technical Association of the Pulp and Paper Industry, 18 East Forty-first Street, New York, N. Y. The method used to determine copper number is described in Bureau of Standards Technologic Paper No. $354 .^{3}$

8 A Modified Method for Determination of the Copper Number of Paper, by B. W. Scribner and W. R. Brode. (B. S. Tech. Paper No. 354.) Superintendent of Documents, Government Printing Office, Washington, D. C. Price, 5 cents. 


\begin{tabular}{|c|c|c|c|c|c|c|}
\hline \multicolumn{2}{|r|}{ 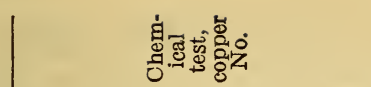 } & \multicolumn{5}{|c|}{ 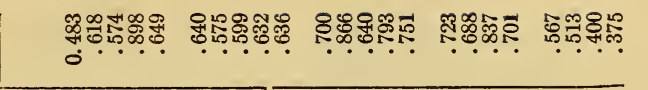 } \\
\hline \multirow{14}{*}{ 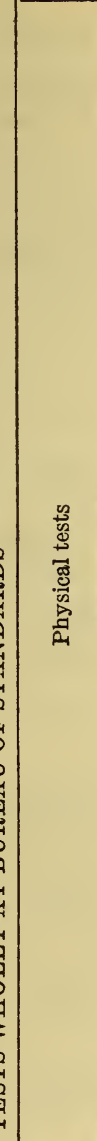 } & 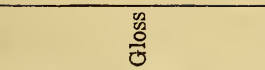 & 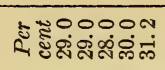 & 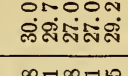 & 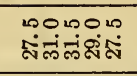 & \multicolumn{2}{|c|}{ 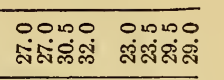 } \\
\hline & 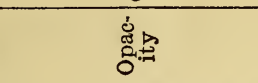 & 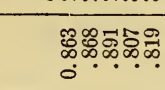 & 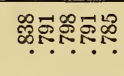 & 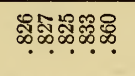 & ॠ & 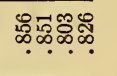 \\
\hline & | & 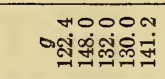 & 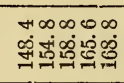 & 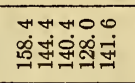 & 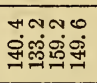 & 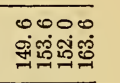 \\
\hline & 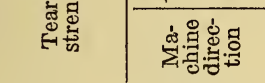 & 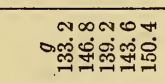 & 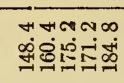 & 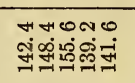 & 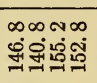 & 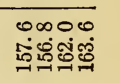 \\
\hline & 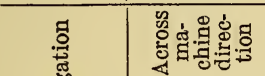 & 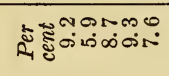 & $\begin{array}{l}-100000 \\
\text { sositis }\end{array}$ & 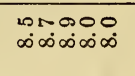 & 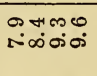 & 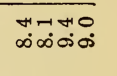 \\
\hline & 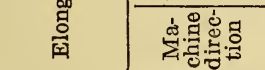 & 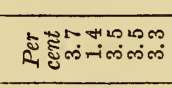 & 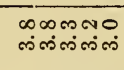 & 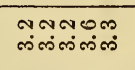 & 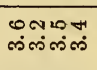 & $\begin{array}{l}\text { Non } \\
\sin \sin \end{array}$ \\
\hline & 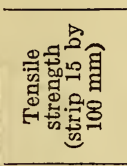 & 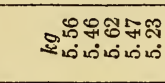 & 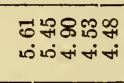 & 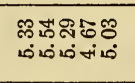 & 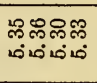 & 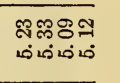 \\
\hline & 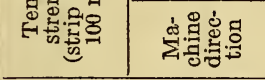 & 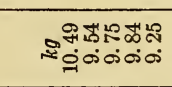 & 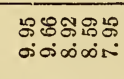 & 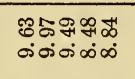 & 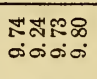 & 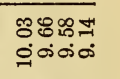 \\
\hline & 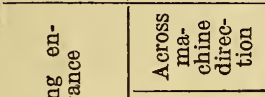 & 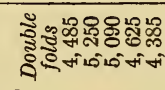 & 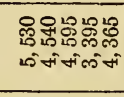 & 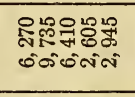 & 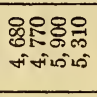 & 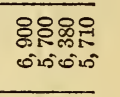 \\
\hline & 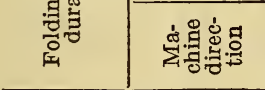 & \multicolumn{2}{|c|}{ 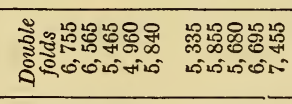 } & 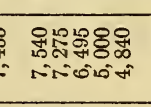 & 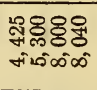 & 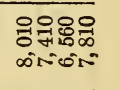 \\
\hline & 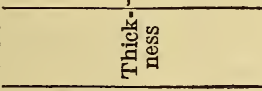 & 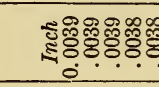 & 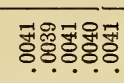 & 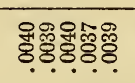 & 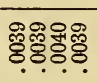 & 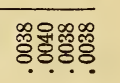 \\
\hline & 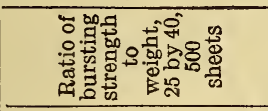 & 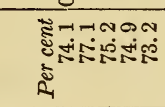 & 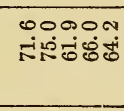 & 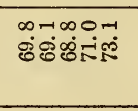 & 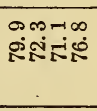 & 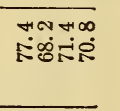 \\
\hline & 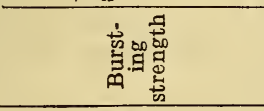 & 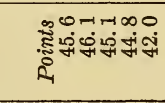 & 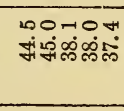 & 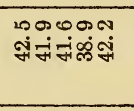 & 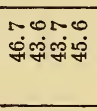 & 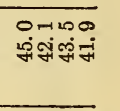 \\
\hline & 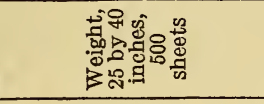 & 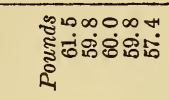 & 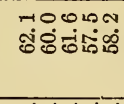 & 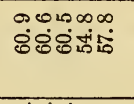 & 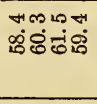 & 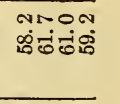 \\
\hline \multirow{2}{*}{ 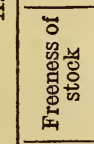 } & 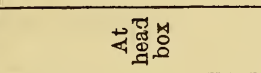 & \multirow{2}{*}{ 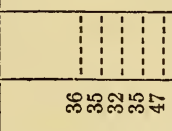 } & \begin{tabular}{l|l|l} 
& & 1 \\
& & \\
\end{tabular} & 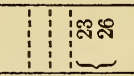 & 무네유 & రిజణణ \\
\hline & 乌⿺辶大 & & 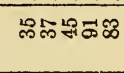 & 개요 & พฉลลన & 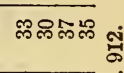 \\
\hline \multicolumn{2}{|r|}{ 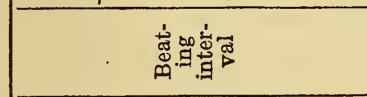 } & 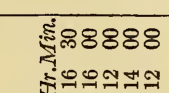 & $\begin{array}{l}88888 \\
\text { ๓쮸궈 }\end{array}$ & 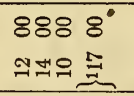 & $\begin{array}{l}8888 \\
\text { m에욤에 }\end{array}$ & 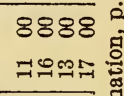 \\
\hline \multirow{2}{*}{ 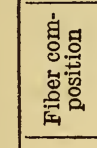 } & ث융명 & 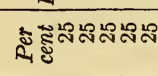 & ㄴํำ이요 & ณณณณ & ฉพละส & 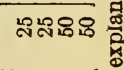 \\
\hline & 兽 & \multicolumn{2}{|c|}{ 竎 } & 2192098 & ํํำ & ํㅜㅇㅇㅇ \\
\hline & 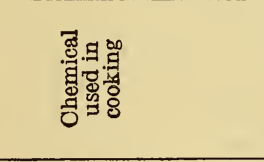 & 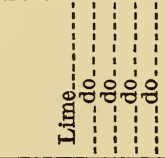 & 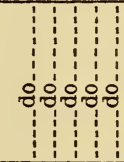 & 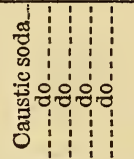 & 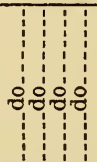 & 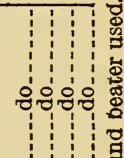 \\
\hline & 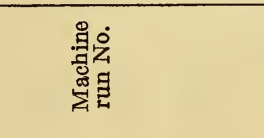 & 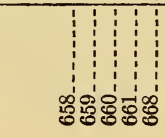 & 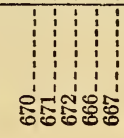 & $\begin{array}{l}0 \\
\vdots \\
8 \\
8\end{array}$ & 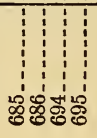 & 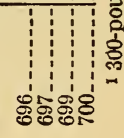 \\
\hline
\end{tabular}




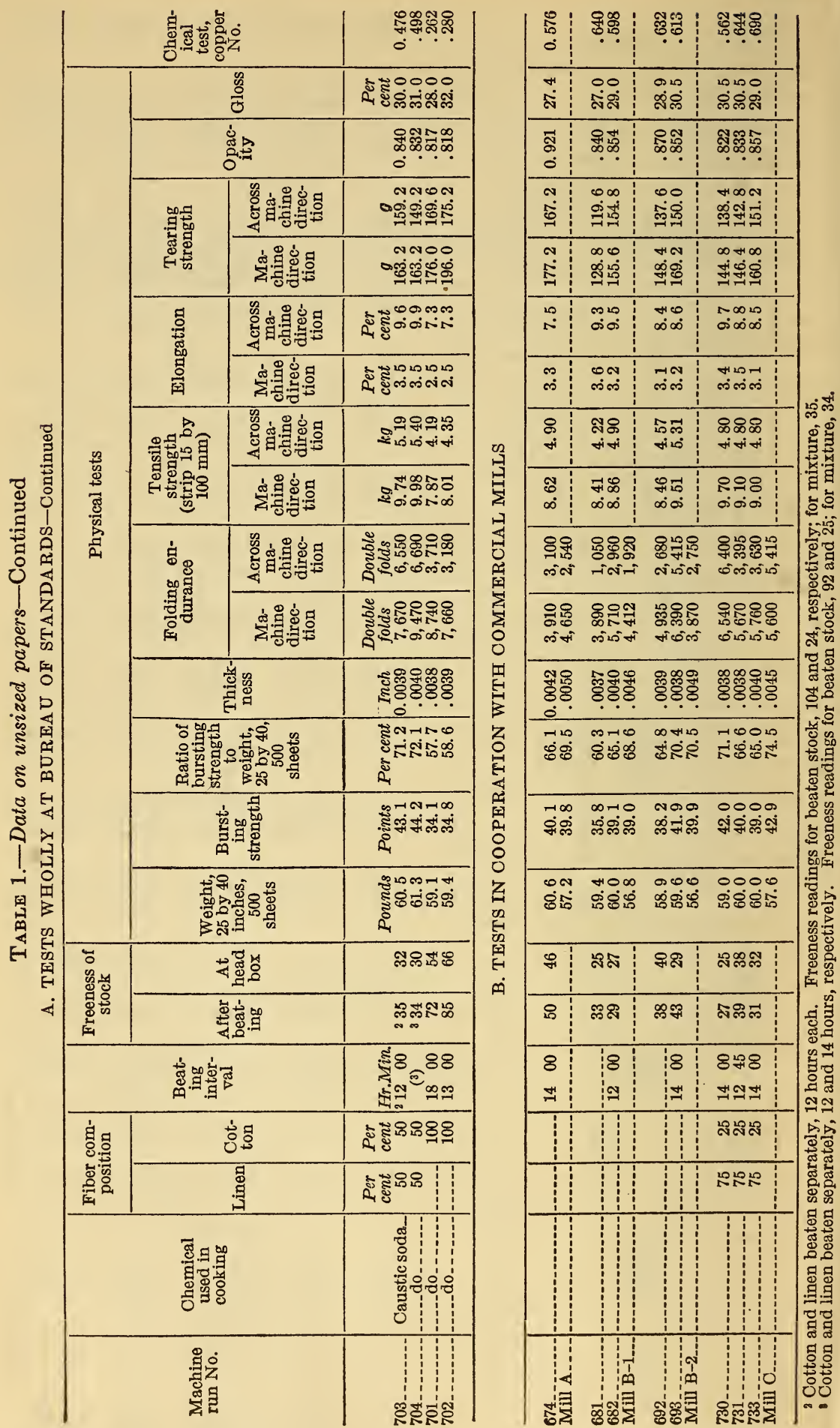


The strength tests show, in general, the resistance of the paper to a rupturing force. Variation in the method of application of the force permits measurements of the different qualities reported in the table as bursting, folding, tensile, elongation, and tearing strengths. The suitability of paper for currency use depends not only upon its strength and durability but also upon its ability to meet the printing requirements. Although the waterleaf or unsized paper is tub-sized before being submitted to the printing operation, the uniformity and general surface condition of the waterleaf sheet are factors in the results obtained. There are no tests to measure these qualities numerically, but they should be considered with the other physical properties in the final evaluation of the paper.

Figure 3 shows graphically the relative characteristics of four papers, of different fiber proportions, as compared with their mean values. Since the relative importance of the several characteristics is still a matter of personal judgment, the results for each are reduced to the same relative basis. The average value ( 25 per cent) of the four samples is taken as the reference basis (zero) in each case.

\section{STOCK PREPARED FROM LIME-COOKED RAGS}

(a) 75:25 Linen-Cotton Mixture.-Run No.658.-The manipulation of the beater roll for this run followed that described in Technologic Paper No. 329, page 98. At the end of 12 hours of beating, however, the stuff still contained small lumps of bunched fibers, commonly called "nits," and the fibers were too long. The beating was therefore continued until these conditions were corrected, $161 / 2$ hours being required for the complete operation.

After the stuff was dropped to the chest, examination of the beater roll showed that the fly bars of the roll were touching the bedplate bars only at one end. Owing to this condition the actual beating surface was much decreased in area and, therefore, more time was required for the beating than in the preceding case to which reference was made. The beater roll was subsequently leveled and adjusted, as was also the lighter bar, before the next test was made.

The measurements of the paper show it to be as strong as that made in the earlier work.

Run No.659.-The beater roll was lowered more slowly for this run than for run No. 658. At the time the beating was in progress the stuff prepared for run No. 658 had not yet been run over the paper machine, but judging by the sound of the beater roll it seemed advisable to beat the furnish more gradually. The fibers were well frayed and the stuff freed from nits at the completion of the process. As shown in Table 1 the paper differed little in folding endurance from that of run No. 658 . 


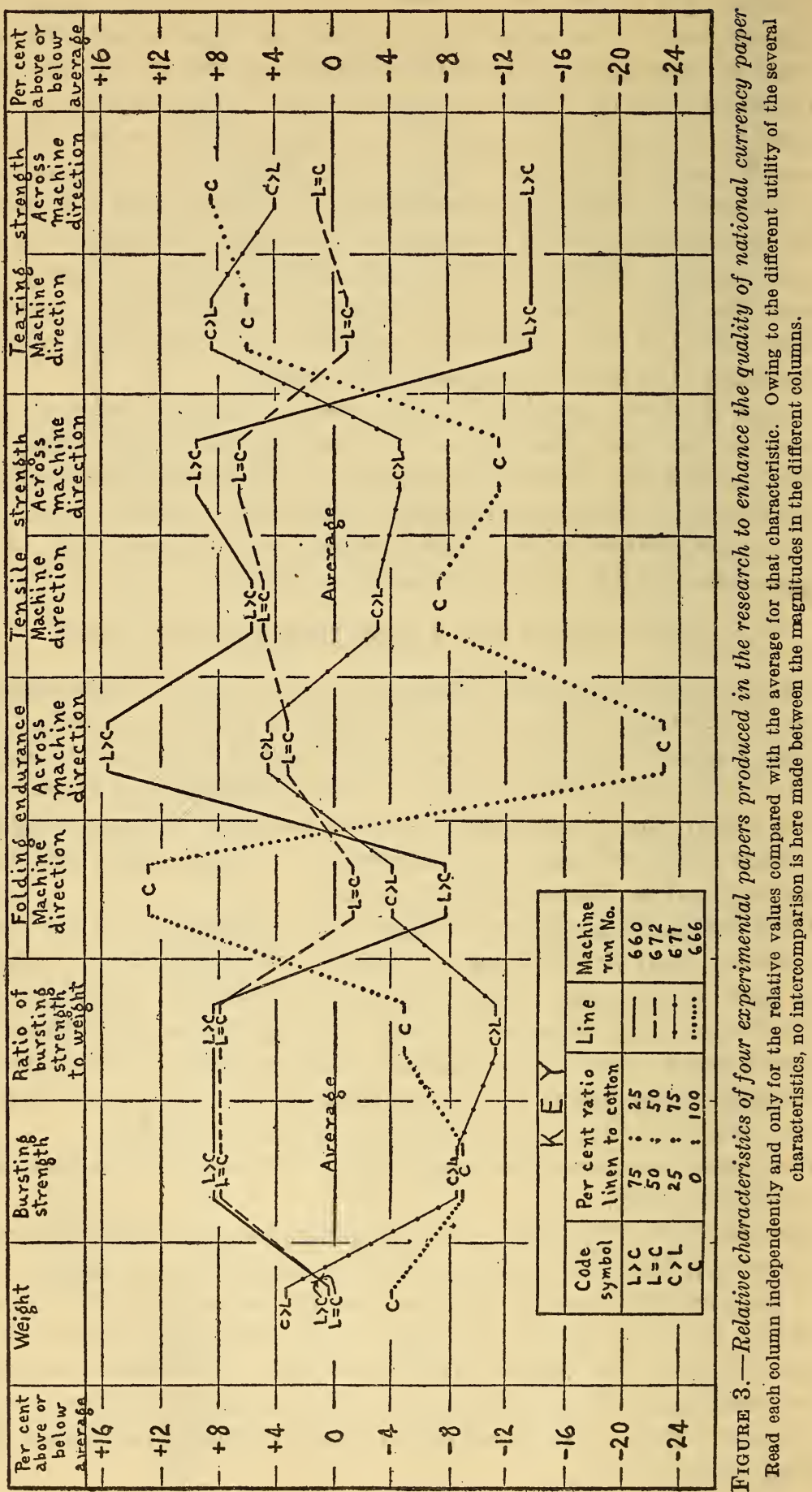


Run No.660.-Satisfactory paper having been produced in the two preceding runs, the stuff for run No. 660 was prepared in accordance with the procedure previously determined as best for a 75:25 mixture (Technologic Paper No. 329) and accepted as standard for the bureau work. Since the test procedure duplicated that for run No. 542 of the earlier work (Technologic Paper No. 329, p. 104), it was expected that the measurements on the paper would agree with those obtained for the earlier run; and inasmuch as the condition of the stock for the runs appeared to be the same, would agree with the measurements for runs Nos. 658 and 659 also. The data obtained confirmed the belief that under controlled and duplicated test conditions practically duplicate results are produced.

Run No.661.-This run differs from run No. 660 only in that the beating was continued two hours longer at the brushing point, zero setting of the roll. Beating for two hours at setting $-1 / 2$ followed, as in the preceding runs. The measurements show the paper to be of good strength, but no better than that made from stock beaten the standard way (run No. 660).

Run No. 668.-This run was not made primarily to obtain additional data for the investigation, but to demonstrate to a group of visiting manufacturers of fine rag papers the methods employed at the bureau in the research on the production of currency paper. The standard beating procedure was followed in preparing the stock. The paper made was apparently as strong as the other papers, but the appearance of the sheet was not as good as usual. When discharged from the beater the stuff contained some long fibers and the Jordan was not large enough to handle it properly. As a result, the stock going to the machine was more or less lumpy, and consequently crushed spots appeared in the paper when calendered.

Run No. 670.-The silk fiber in United States currency has until recently been limited in distribution to two narrow bands in the paper, one on each side of the portrait on the printed currency. The Treasury Department was considering changing the specifications for the paper to require that the silk fibers be distributed uniformly throughout the sheet. Information as to the amount of silk fiber that would be needed was desired. Run No. 670 was made for that purpose and silk fibers were therefore incorporated in the stock as a distinctive feature.

The beating was according to the standard procedure, but at the end of 12 hours the stuff was not clear, not free from nits, and an additional hour was required to complete the operation. The presence of the silk caused no trouble in the paper-machine operation.

(b) 50:50 Linen-Cotton Mrxture.-Run No. 671.-The beating was in accordance with the standard procedure, but an extra hour was required to clear the stuff. 
(c) 25:75 Linen-Cotton Mixture.-Run No.672.-The half stuff was beaten according to the regular procedure.

(d) 100 Per Cent Cotton.-Run No. 666.-No difficulty was encountered in this run. The paper was well formed and appeared free from fuzz. The measurement also showed it to be very good in strength.

Run No. 66\%.-The beater roll was lowered much more slowly in the preparation of the stuff for this run than for the preceding. It was hoped that by increasing the beating time, decreasing the pressure of the beater roll proportionally, "slower" stock and consequently stronger paper would be obtained. The beating interval was 17 hours, but the paper did not show any appreciable increase in strength over that of run No. 666 .

\section{STOCK PREPARED FROM RAGS COOKED WITH CAUSTIC SODA}

Except that caustic soda was used instead of lime in the cooking liquor for the rags, the paper-making procedure for the remainder of the runs also was the same as that described in the earlier publication. The amount of caustic soda added differed with the character of the rags furnished to the boiler. The amounts used for the different kinds of cooks are given on page 903 .

(a) 75:25 Linen-Cotton Mixture.-Run No. 662.-The stuff for this run was prepared in accordance with the regular method of beating. The paper made seemed to be softer than that made from rags cooked with lime. Table 1 shows it to have a higher folding endurance also.

Run No. 663.-The beating for this run differed from that for the preceding only in that the process was continued two hours longer when the roll was at the $-1 / 2$ setting. The measurements show that the paper produced had a higher folding endurance than that of run No. 662 (12 hours of beating).

Run No.669.-The conditions relative to this run were the same as for the preceding two runs, except that the beating time was only 10 hours.

Runs Nos. 683 and 684.-The 50-pound beater was used in preparing the stuff for all the machine runs except Nos. 683 and 684 . For these runs the 300-pound beater was employed. The beating procedure planned was an adaptation of the standard method suitable for the larger beater, but during the preparation of the stuff it was necessary to keep the beater roll at the +2 setting for 4 hours, because of an overload of more than 15 per cent on the motor. If there had been sufficient motor capacity, the roll would have been at the zero setting in $7 \frac{1}{2}$ hours, instead of being only at the +2 setting. Because of the insufficient motor capacity, the required beating time was increased to 17 hours. This fact should be considered in comparing 
the test data for the runs. It is believed, however, that with a motor large enough to operate the beater, the results obtained with the 300-pound beater would compare favorably with those for the 50 -pound one.

The beaten stuff was pumped from the Jordan directly to the paper machine. Screen plates with 0.024-inch slots were used for machine run No. 683, but 0.036 -inch cuts were used for run No. 684 . (The plates with the 0.024-inch openings were used for all the other tests.) The test data on the papers of the two runs are practically the same. Screening the stock through slots of different gage caused no resultant differences in the sheets.

In all the previous work the cotton rags, light-colored linen rags, and dark-colored linen rags had been kept separate throughout the conversion into half stuff. The beater charges were mixtures of the different half stuffs. For the remainder of the runs on stock composed of 75 per cent linen and 25 per cent cotton, however, the rags were all cooked together.

Runs Nos.685 and 686.-Different methods were used in bleaching the half stuff for runs Nos. 685 and 686 to determine their comparative effect on the strength of the fiber. The boiler furnish was 75 per cent linen and 25 per cent cotton, and the chemical agent was 4 per cent of caustic soda. The cooked rags were divided into two equal lots. One part was washed, bleached, washed again, and beaten, without removal from the beater tub. Machine run No. 685 was on the stock thus prepared. The remainder of the cook was washed and after being partially bleached in the washer was discharged into the drainer, where the bleach was allowed to become spent and the final washing given the half stuff. The half stuff was beaten similarly to that for run No. 685. The stock was run over the paper machine as run No. 686 .

The test data show very little difference in the papers. It apparently makes no difference in the quality of the paper whether the cooked rags are washed immediately after bleaching and converted into stuff without removal from the beater or whether the drainer system of bleaching is used and the washed half stuff then returned to the beater for the final reduction, providing, of course, that in the latter operation an excessive amount of bleach is not used. To prepare stuff commercially according to the first method, run No. 685, more beaters would be needed, however, and it is doubtful if the results obtained would warrant the increase in equipment required.

Runs Nos. 694 and 695.-In making the cook for these runs the rags were furnished to the boiler and allowed to stand therein overnight. The next morning the regular amount of cooking liquor was added. At that time it was noted that the boiler contained a greater volume of liquor than it had for any of the previous cooks. The 
presence of the extra amount may have been due to the fact that the main water valve had been left open and the possibility that one of the valves at the cooker may have leaked. The greater quantity of water weakened the strength of the cooking liquor and also reduced the space in the cooker available for steam. Owing to the latter condition the usual cooking temperature could not be maintained, although greater pressure in the boiler was recorded. The pulp was reduced to half stuff and bleached in the usual way.

The beating procedure for run No. 694 was in accordance with the standard method. The time required was 13 hours. The stuff seemed much more harsh than usual, however, which condition was doubtless caused by the circumstances described relative to the cooking. Practically no trouble was experienced in running the stock over the paper machine, but the paper produced was harder than that made from the other caustic soda cooks.

The stock for run No. 695 was prepared by somewhat different beating procedure. After the beater was furnished the roll was set at +6 and was lowered at the rate of one-half turn an hour until the $+1 / 2$ position was reached. The total beating time was 16 hours. No difference was noted in the strength of the papers made in the two runs, however.

Runs Nos. 696 and 697.-In order to check the two preceding runs a similar cook was made. The half stuff was prepared in the usual way.

For run No. 696 the beating operation was in accordance with the standard procedure, and the time required was 11 hours. The test data for the paper check very closely with those for run No. 694 , but the paper had a softer feel. Figure 4 is a photomicrograph ${ }^{4}$ of the stuff as it was dropped from the beater, ready for the paper machine. The photomicrograph (also those of figs. 5 to 8 ) was made at a magnification of 100 diameters, but for the reproduction herein the magnification is about 60 .

The beating procedure employed in the preparation of the stuff for run No. 697 was like that for run No. 695. The data for the paper of this run agree well with those for runs Nos. 694, 695, and 696.

(b) 50:50 Linen-Cotton Mixture.-Runs Nos. 699 and 700.-A cook was made on a furnish of 50 per cent linen and 50 per cent cotton rags, with 3 per cent of caustic soda. Two paper machine runs, Nos. 699 and 700, were made on stock prepared from the cooked mixture. The beating intervals were 13 and 17 hours, respectively. The papers made seemed very good and compared very favorably in strength with papers made from 75 per cent linen and 25 per cent cotton stock.

Figure 5 shows the condition of the stuff for run No. 699 at the completion of the beating, 13 hours.

4 Photomicrographs were made by R. E. Lofton, associate physicist, Bureau of Standards. 


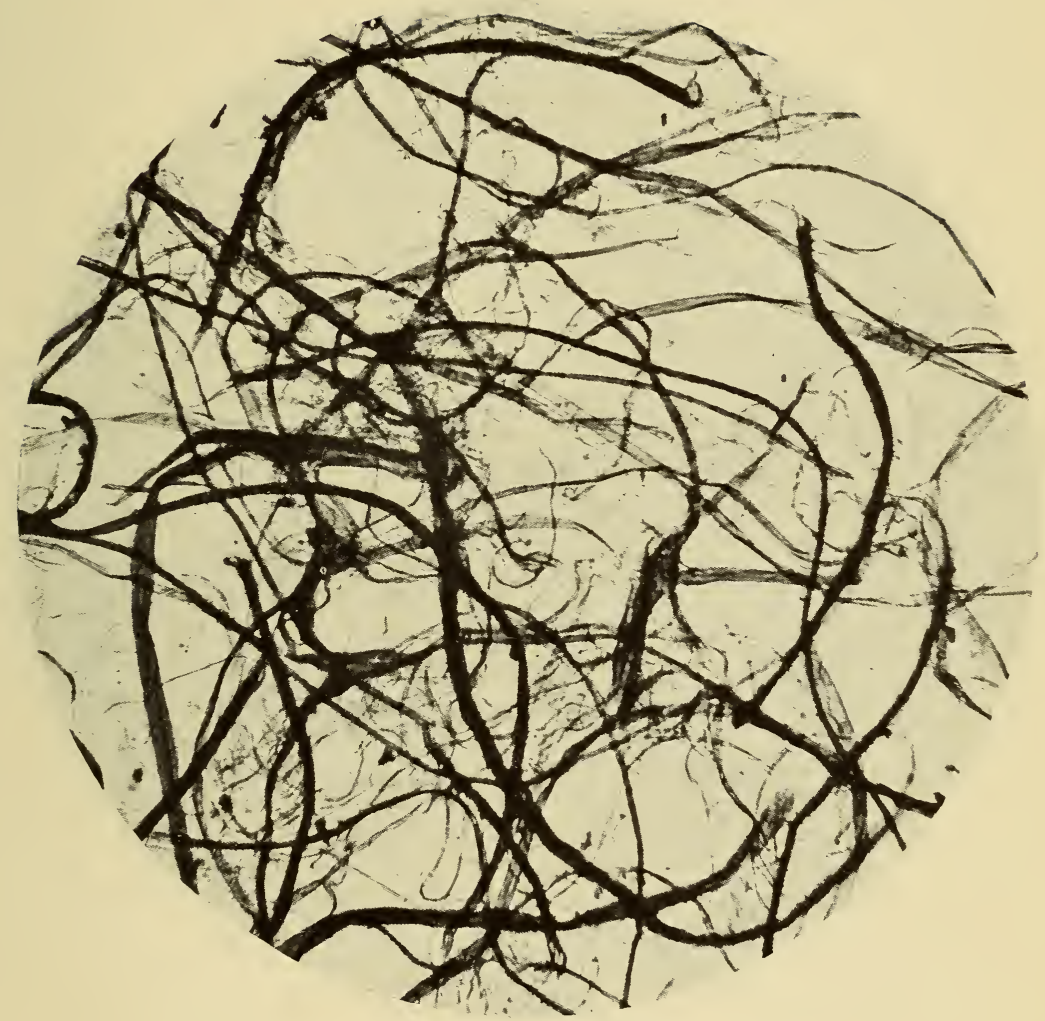

Figure 4.-A 75:25 linen-cotton mixture

After completion of the beating (11 hours). Stock for paper machine run No. 696 . 


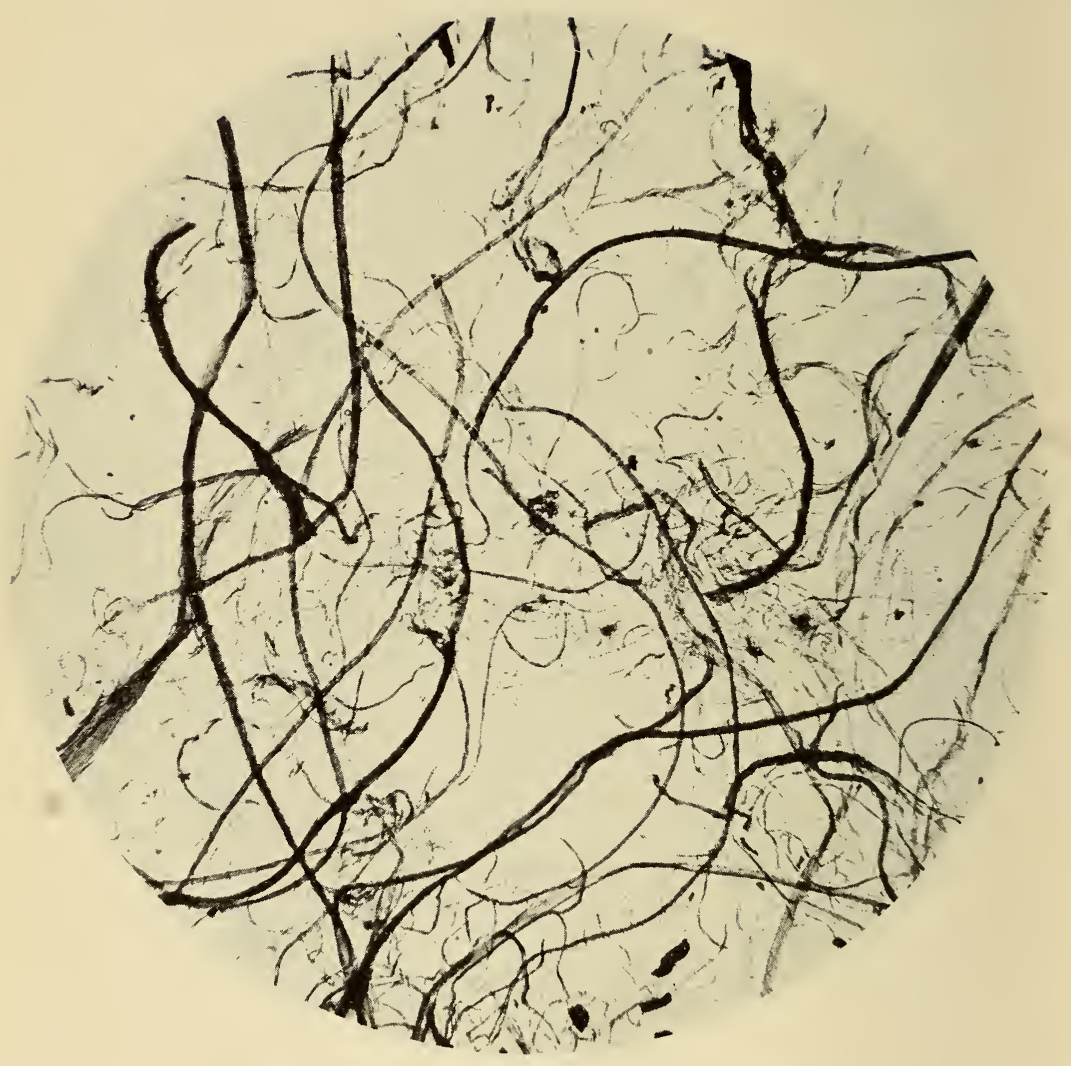

Figure 7.-A 100 per cent linen stock

After completion of the beating (12 hours). Stock was mixed with cotton before being run over the paper machine, run No. 703. 


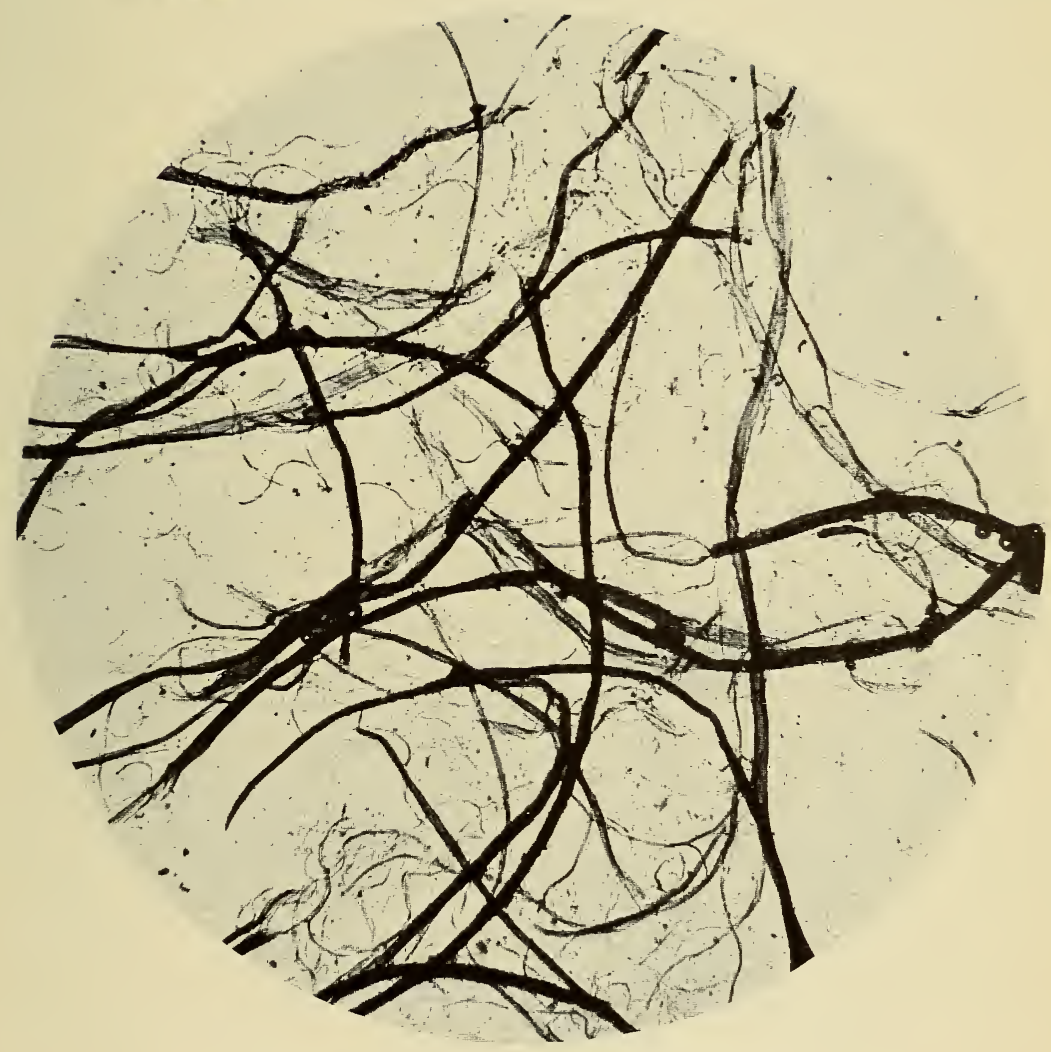

Figure 8.-A 50:50 linen-cotton mixture

The cotton and linen were beaten separately (figs. 6 and 7 ), and the stuffs mixed in the machine chest. Stock for paper machine run No. 703 . 
Runs Nos. 703 and 704.-Preparatory to making runs Nos. 703 and 704 two cooks were made. The boiler furnishes were 100 per cent cotton and 100 per cent linen. The resultant pulps were kept separate throughout the preparation of the stuff. The beaten stuffs, the cotton and the linen, were mixed together in the machine chest.

The standard beating procedure was followed for machine run No. 703. The freeness reading for the cotton stuff at the completion of the beating was 104 , and for the linen, 24 . The reading for the final mixture was 35 . Figure 6 shows the condition of the 100 per cent cotton stuff after the 12 hours of beating, and Figure 7, the condition of the 100 per cent linen stuff. The photomicrograph shown in Figure 8 is of the mixed stuffs, 50 per cent cotton and 50 per cent linen, and is therefore comparable with that of Figure 5.

For machine run No. 704 the cotton was beaten as for run No. 703, but the linen was given a longer brushing period. The beating intervals were 12 and 14 hours, respectively. The freeness reading for the cotton stock was 92 ; for the linen, 25 ; and for the final mixture, 34.

As shown in the table, the papers of runs Nos. 703 and 704 differ little in strength characteristics, but are somewhat superior to the paper of run No. 699, for which the cotton and linen half stuffs were mixed together in the beater, and for which the regular beating procedure was followed.

The freeness reading of the stuffs for runs Nos. 703 and 704 indicate that linen fibers have proportionally greater influence than cotton on the freeness of a mixture of these materials.

(c) 100 Per Cent Cotton.-Runs Nos. 701 and 702.-After the beater was furnished for paper machine run No. 701 the roll was set at +6 and was lowered at the rate of one-half turn an hour until the setting $+1 / 2$ was reached. The rate was then varied according to the condition of the stock. The total beating time was 18 hours. The standard beating procedure was employed for the stuff of run No. 702 , and the beating interval required was 13 hours. Both runs were considered very good for 100 per cent cotton stock.

\section{PAPER-MAKING TESTS IN COOPERATION WITH COMMERCIAL MILLS}

As before mentioned, fine paper of such great strength as that developed at the bureau in the currency investigation had not previously been produced commercially. As a result of the research, however, three manufacturers of fine rag papers instituted similar experimental tests on a commercial scale, and requested the assistance of the bureau in the development work. The cooperative study included visits to the commercial mills in an advisory capacity, and paper-making tests at the bureau and in the commercial mills for comparison of their respective manufacturing processes. Table 1 
includes data on the papers produced. The commercial mills are designated therein as "A," "B," and "C."

\section{MILL A}

Run No. 674 was made in the bureau paper mill from half stuff received from manufacturer A. Paper made in mill A from half stuff from the same batch was also submitted and is listed in the table as mill A.

During the beating of the half stuff in the bureau mill the beater roll was lowered very gradually, and not below the brushing point. The appearance of the finished sheet was very good but the feel was harsh, not soft and smooth as that of the bureau papers had been. The half stuff furnished to the beater was likewise harsh, as if it contained much more cotton than linen fiber.

Although the folding endurance measurements show the paper made at the bureau to be more uniform in formation, the semicommercial work checks the commercial run very satisfactorily, as indicated by the test data. Compared with papers of the previous bureau tests, however, the test results indicate that the rags used in mill A were not of as good paper-making quality as those employed at the bureau.

\section{MILL B}

Stock, half stuff, and paper samples, representing the same fiber at the corresponding stages in the manufacturing process, were submitted by mill B. Papers made at the bureau from the stock and the half stuff are indicated in the data by runs Nos. 681 and 682, respectively. Measurements on the paper samples submitted appear under the designation mill B-1.

The prepared stock submitted was described by the manufacturer as "wet stock taken from the doctor on the couch roll, which represents our beaten, jordanned, and screened fiber ready to be made into paper." 5 Preparatory to running it over the bureau's paper machine, the stock was mixed with water in the beater to the consistency regularly used in the bureau tests. It was then dropped to the beater chest and from the chest was run through the screen to the paper machine. The test data for run No. 681 are on the paper made from this stock.

The formation and appearance of the sheet were very good, but the strength was less than that of the paper sample submitted for the same stock. This condition was expected, however, as it has been the experience of the bureau that stock screened and run over the paper machine a second time does not give as strong a sheet as that

A doctor is a scraper employed to keep the surface of a roll clean. By its use here the wet stock was removed from the machine. 
made in the original run. Much better comparison of the corresponding processes in the two mills would have been afforded if the stock sent by manufacturer B had been taken before being screened but after it had passed through the Jordan refiner. The stock used at the bureau would then have been comparable in condition to that going onto the paper machine in the commercial mill.

The half stuff received from manufacturer B was shorter than that regularly prepared at the bureau in the experimental work. It appeared to have received too much cutting, but not enough brushing. The subsequent beating, jordanning, screening, and papermachine operation were in accordance with the procedure at the bureau. The appearance and formation of the paper produced were fairly good, but the folding endurance was not as nearly uniform in the two directions of the sheet as for the papers made wholly at the bureau. The greater difference was probably due to the fibers having been cut more and brushed out less in the preparation of the half stuff at mill B.

The bureau suggested that if manufacturer B desired additional comparative tests, the stock submitted be taken after the jordanning but before the screening, and the half stuff supplied be prepared by more brushing and less cutting in order to have the fibers long but well frayed. Manufacturer B wished to have further data and submitted additional test materials accordingly. Machine runs Nos. 692 and 693 and the data designated mill B-2 are for the latter materials.

The stock received was, as before, mixed in the beater to the consistency used for the bureau work, discharged into the beater chest, and thence run through the screen to the paper machine. The paper made from this stock should be more nearly comparable to that made in the experimental run in the commercial mill. As noted in the table, runs Nos. 692 and mill B-2 check very closely. The data show that with the same stock the results obtained on the bureau's semicommercial paper machine check those obtained in a commercial mill.

The half stuff received was given 14 hours of beating. On completion of the process the fibers were of good length and the stuff was clear and appeared in condition to give a good sheet. The stock was pumped from the Jordan directly to the paper machine for run No.693.

Comparison of the test data shows that paper made from manufacturer B's half stuff, beaten in the bureau mill in accordance with its regular procedure, has approximately twice the folding strength of that made from the stock prepared in mill B from the same half stuff. It will be noted also that the folding endurance is much more nearly uniform in the two directions of the sheet, and it is believed that with papers of this type there is less distortion in the printing 
operation. Any dissimilarity in the two lots of stock must have been due to difference in methods of beating. The beating procedure recommended by the bureau in its earlier publication on the production of experimental currency paper-that is, very gradual application of roll pressure-proved more satisfactory than manufacturer B's method.

\section{MILL C}

As a part of the commercial development of the type of paper produced experimentally in the currency research, manufacturer $\mathrm{C}$ submitted three boxes of half stuff for tests to determine the effect of temperature on the stock in the beating process. Paper made in the mill from the same batch of half stuff was also received. Three beaters of stuff were prepared at the bureau, each at different temperature. The corresponding paper machine runs made were Nos. 730,731 , and 733 .

For the first machine run, No. 730, the half stuff was beaten according to the bureau's regular procedure. The beating time was 14 hours. The paper of the run was well formed and checked closely the strength of the paper sample submitted by mill C.

For machine run No. 731, the beating was practically according to the bureau practice, but after $71 / 2$ hours of beating the temperature of the furnish was raised approximately $30^{\circ}$ - to between $148^{\circ}$ and $153^{\circ} \mathrm{F}$. - the beating being uninterrupted meanwhile. Since the increased heat expanded the bars in the roll and the bedplate, the subsequent beating action was harder than that for the previous run, No. 730, and the reduction of the stock was therefore more rapid. The stuff was dropped to the machine chest after $12^{3 / 4}$ hours of beating and was then shorter than that for run No. 730 .

In rinsing the stuff from the beater, cool tap water was used. The temperature of the diluted stuff in the machine chest was $105^{\circ} \mathrm{F}$. A hand sheet made from the stuff just before it was discharged into the chest was of a brownish cast in color, but a sheet made from the cooler stock in the machine chest did not show the brownish color.

The half stuff for run No. 733 was given easier beating treatment. The roll was lowered only one-half turn an hour and the final setting was $+\frac{1}{2}$. After the first day of beating, 6 hours and 40 minutes, the temperature in the beater was gradually raised during the remainder of the operation. The beating time required for the stuff was 14 hours and the final temperature was $149^{\circ} \mathrm{F}$.

Instead of the beater contents being dropped to the chest on the completion of the beating, the stuff was allowed to stand in the beater and cool down gradually, to permit the maximum injury to the stock by the heat. The following morning after the stuff in the beater was circulated and its temperature found to be $120^{\circ} \mathrm{F}$., steam was again turned on and the temperature raised to $150^{\circ}$. The stuff 
was then rinsed from the beater into the chest with warm water. The final temperature in the chest was $123^{\circ} \mathrm{F}$.

Although the lowest roll setting was only $+1 / 2$, the increased heat in the beater had expanded the bars in the roll and bedplate and caused the subsequent beating action to be much harder than that for run No. 730 .

Judged by general appearance there was practically no difference in the color of the papers of the three runs. As was expected there were differences in the strength values of the sheets, because of the harder beating given when heat expanded the roll and bedplate bars. The effect of the heat produced by the beating action on the fibers may be different, however, from that occurring at similar temperatures obtained by the application of steam.

The temperature in the beater is, of course, lower when soft, well-cooked pulp is used than when harsher, undercooked material constitutes the furnish. The beating action is more rapid, and therefore the time required for the reduction is less for the softer furnish.

\section{GLUE SURFACE-SIZING TESTS}

Currency is printed from engraved metal plates. In order that the fine lines may print with clear definition the paper is dampened. The sunk engraving is filled with ink and the dampened paper is forced against the plate by great pressure to withdraw the ink and receive the impression. The excellence of the printing on the finished currency is the main hindrance to effective counterfeiting.

The wetting quality of the paper is an important factor in the printing results. Any considerable variation in the resistance to wetting interferes with the mechanical handling of the paper during the conversion into currency and influences both the quality and the quantity of the finished work. Printing tests on various samples of experimental currency papers have shown that printing of superior merit can be produced on unsized paper, but that such paper requires extraordinary care in wetting, printing, drying, and incidental handling through the course of operations. Surface sizing is considered a requisite for satisfactory printing results on a production basis with the wet intaglio process, but the further work contemplated may show that the sizing operation can be eliminated.

The properties imparted to paper by surface sizing afford a means of control of the degree of wetness of the paper. The wetting quality is affected considerably by the amount of sizing present. To give currency paper as good printing quality as possible, experimental tests were made to determine the amount of glue sizing necessary to avoid interference with production. It was hoped that lighter sizing would suffice and that the printings would therefore approach the desirable characteristics of the unsized sheets. The sizing tests were 
made in the paper mill of the Bureau of Standards, and the subsequent printing tests were made at the Bureau of Engraving and Printing.

To establish a standard procedure for applying glue sizing to the paper-machine products, preliminary tests were made to determine the comparative value of alum and formaldehyde as glue preservatives, and the effect of the temperature of the glue bath. Two sizing solutions were employed. The glue content of each was 6 per cent, but one contained alum as the preservative and the other formaldehyde. The proportions of alum and formaldehyde added were representative of commercial practice and, based on the weight of the glue, were 6 per cent and $1 / 4$ per cent, respectively. One grade of waterleaf or unsized paper was used throughout the tests. Four runs were made with each solution. The treated papers were calendered and tests were made thereon. The data obtained are reported in Table 2. In addition to the physical properties reported for the corresponding unsized papers in Table 1, the resistance of the moist paper to abrasion is also included. Currency in service is often subjected to handling with moist hands and the wet-rub test ${ }^{6}$ is believed to simulate these conditions.

\footnotetext{
- The apparatus and method of test were developed at the bureau and are described in a previous article, A Wet-Rub Tester for Paper, by F. T. Carson and F. V. Worthington, Paper Trade J., 84, No. 2, pp. 43-44; Jan. 13, 1927. .
} 


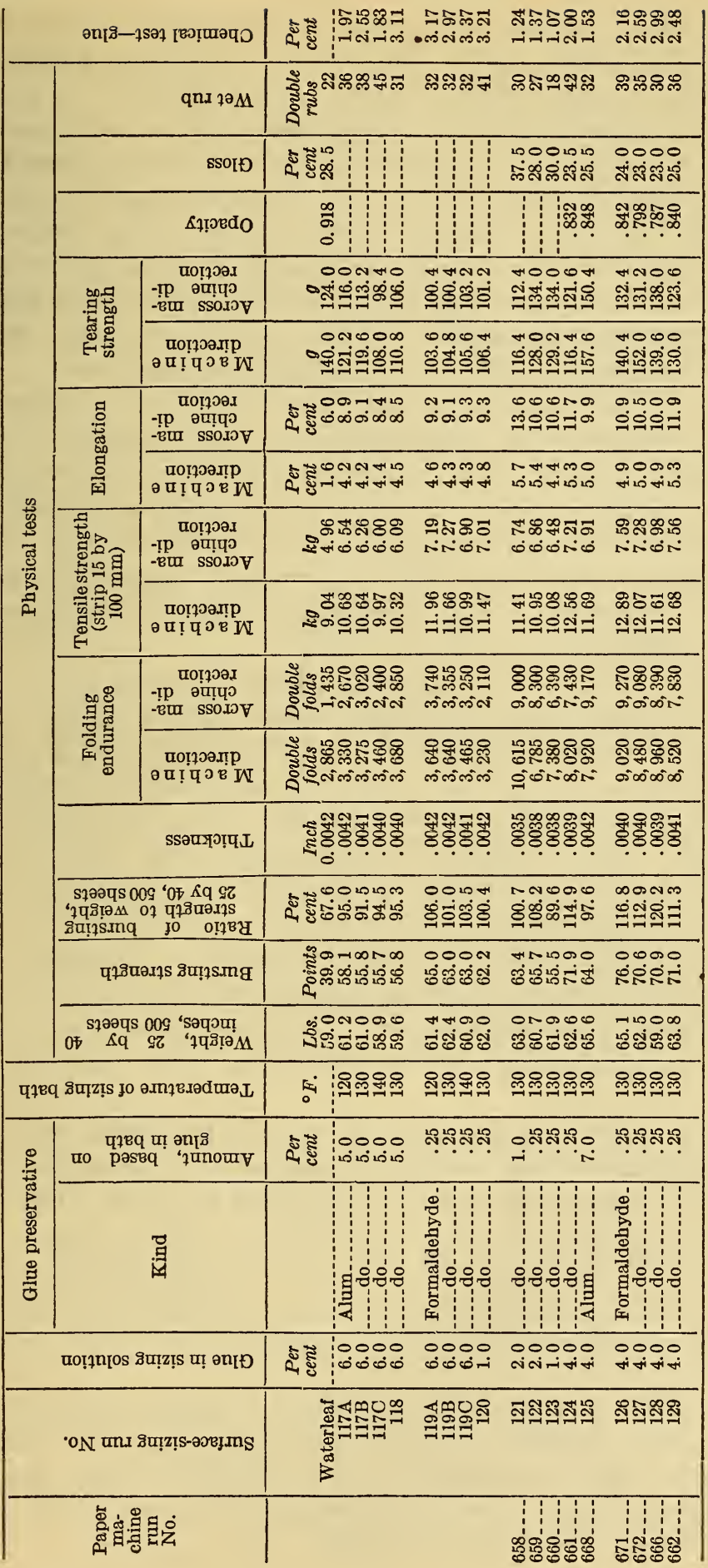


For the first three surface-sizing, runs, the temperature of the glue bath was $120^{\circ}, 130^{\circ}$, and $140^{\circ} \mathrm{F}$., respectively. Each run was made on the day that the glue solution therefor was prepared. To determine whether the age of the glue solution was a factor in the results obtained, the solution for the fourth run was permitted to stand in the vat three days at room temperat,ure. Upon examination at the end of that time no bacterial growth was observed on the surface of the solutions and no deterioration or change in odor was noted. The solution containing alum had jellied, however, but that to which the formaldehyde had been added had the liquidity of water. Both solutions were warmed to $130^{\circ} \mathrm{F}$. for the surface-sizing runs.

The data of Table 2 indicate that the sized papers were somewhat stronger when formaldehyde was used as the glue preservative than when alum was employed. Other advantages in the use of formaldehyde are the absence of acidity in the sizing and the more uniform penetration of the glue solution because of its greater fluidity. The latter is of direct value, since such uniformity is essential to even distribution of moisture in the mechanical wetting of the paper preparatory to printing.

The constants accepted from the preliminary tests for use in surface sizing the experimental currency papers were 0.25 per cent of formaldehyde (based on the weight of glue) and $130^{\circ} \mathrm{F}$. temperature. Since the tests did not show any advantage in aging the glue solutions, the solutions for the currency tests were used the day prepared. Nine additional surface-sizing runs were made. Measurements for the sized papers are included in Table 2 and data for the corresponding waterleaf sheets were given in Table 1.

The experimental currency papers employed for the first five surface-sizing runs were of 75 per cent linen and 25 per cent cotton fiber composition. The concentration of the glue solution was varied, and in one case the amount of formaldehyde. The runs were as follows.

Run No. 121.-The concentration of glue in the sizing bath for run No. 121 was 2 per cent and the proportion of preservative used was 1 per cent, based on the quantity of glue in the bath. The proportion of glue retained in the sized paper was 1.24 per cent. As shown in the table, the paper had a very high folding strength. The increased quantity of formaldehyde increased somewhat the hardening of the glue, which was doubtless the cause of the greater folding strength.

Runs Nos. 122 and 123.-The concentration of glue in the sizing bath for runs Nos. 122 and 123 was 2 and 1 per cent, respectively, and the corresponding proportions of glue retained in the sized papers, 1.37 and 1.07 per cent. One-fourth per cent of formaldehyde was used as the preservative in each solution. 
Run No. 124.-The percentage of glue retained in the sized papers of the preceding three runs was, in general, only about one-half of that found in the commercial paper being used for the Government currency. To afford comparison of the experimental and commercial papers in the printing processes, particularly in the wetting operation, the concentration of the glue in the sizing bath for run No. 124 was increased to 4 per cent. The proportion of glue retained in the sized paper was 2.00 per cent.

Run No.125.- Since the amount of glue in the sized paper of run No. 124 approximated that in the commercial papers, it was decided to make a similar run using alum as the preservative, as is general in commercial practice. The concentration of glue in the sizing bath was 4 per cent, as in the preceding run, and the proportion of alum, 7 per cent. The glue retention in the sized paper was 1.53 per cent, the decrease doubtless being due to the lesser liquidity of the sizing solution.

The surface-sized papers for runs Nos. 121 to 125 were submitted for printing tests by the regular processes at the Bureau of Engraving and Printing. Those of the first four runs wet without difficulty and caused no trouble in the printing. Even the paper with only 1.07 per cent of glue proved satisfactory, and excellent impressions were obtained upon it.

The paper of surface-sizing run No. 125, in which alum was used as the preservative, wet irregularly and required sorting, however, and some of the sheets needed to be rewet. These conditions further indicated that the glue sizing penetrated the sheet less uniformly when alum was used in the bath than when formaldehyde was employed.

The conditions subsequently adopted as standard for the remainder of the surface-sizing tests were 4 per cent glue solution as sizing bath, one-fourth of 1 per cent formaldehyde as glue preservative, and $130^{\circ}$ F. as temperature of the bath.

Four additional surface-sizing runs were made. The papers for runs Nos. 126 to 128 were from lime-cooked stock, 50 per cent linen and 50 per cent cotton, 25 per cent linen and 75 per cent cotton, and 100 per cent cotton, respectively. Run No. 129 was on paper made from stock 75 per cent linen and 25 per cent cotton, pulped by the caustic-soda process.

It will be observed from Table 2 that the glue retention increased with increasing amounts of cotton; also, that the paper of run No. 129, 75 per cent linen and 25 per cent cotton, caustic-soda cooked, had a higher glue content than that of run No. 124, similar fiber composition but lime cooked. The greater glue retentions were due in a large measure to the greater softness of the waterleaf papers.

In comparing the test data of the surface-sized papers, Table 2, with those for the unsized sheets, Table 1 , the effect of the surface $77886^{\circ}-29-7$ 
sizing is evident. It produced in all cases a marked increase in the bursting strength, tensile strength, and folding endurance of the papers. The folding endurance, which is used as the principal criterion of strength for currency paper, is several hundred double folds more for the sized than for the waterleaf sheet, although the unsized sheet itself had a very high resistance in this respect.

In the wet intaglio process used for printing currency, the paper is wetted, printed under high pressure on one side, and dried. These operations are then repeated when the other side of the paper is printed. Such treatment is inimical to glue sizing and there is a possibility that some of the strength imparted to the paper by the glue sizing is destroyed as a result of these operations. Tests of their effect on the strength of the paper have given conflicting results. In some cases there was apparently no loss in strength, while in other cases the paper had apparently lost all of its glue-sizing strength. Quite likely the effect of the printing processes varies with variations in them and in the properties of different lots of paper, but in no case have the printing operations been found to affect the basic fiber strength of the paper. From these considerations it is thought desirable to specify the strength of the unsized paper, as well as that of the sized. This practice is desirable also in the case of commercial rag papers where a high degree of endurance is desired.

It should be borne in mind in considering the sizing results described that they may not apply directly to commercial bonds and ledgers, as they are sized for a different purpose than is currency paper. The latter is surface sized primarily to make it work satisfactorily through the wetting operation of the printing process. In bonds and ledgers the primary function of the surface sizing is to give good writing and erasing quality to the sheet.

\section{SUMMARY AND CONCLUSIONS}

A previous publication, Technologic Paper No. 329, described the earlier production of experimental currency paper in the Bureau of Standards semicommercial paper mill. The folding endurance of the paper, which is generally considered the test best adapted for indicating the probable resistance to continued handling, was double that of the commercial paper being supplied for Government use when the investigation was initiated. The increase in strength was attributed chiefly to the method of beating the fibers. The investigation also demonstrated the applicability of the experimental manufacturing procedure to commercial production. As a result of the study the folding strength specified in the current contract specifications for United States currency paper is more than triple that previously required, and paper meeting the requirements is being supplied without increased cost to the Government or in the manufacturing process. 
The Treasury Department subsequently requested additional study of the paper manufacturing processes, with a view to further improving the quality of currency paper. Paper possessing the characteristics required of currency paper and having the strength of the experimental papers had not been produced commercially previous to the investigation. Following the earlier study several manufacturers of high-grade rag papers instituted experimental tests of similar nature and also requested the cooperation of the bureau in establishing the best manufacturing procedure. The present publication relates to the continued research at the bureau. The test results indicate the following conclusions:

Either caustic soda or lime can be used satisfactorily as the cooking chemical in the production of paper of currency quality. The test papers made from half stuff prepared by the caustic-soda process were fully as strong as those made from lime-cooked stock and had a softer feel, making them, therefore, somewhat better in printing quality.

Caustic soda cooking solution has its maximum strength at the time added to the rags, and since caustic soda is a strong alkali, it may, therefore, injure the paper-making fiber if used in excess. It is important that the initial solution be of definite concentration, and control methods should be used in its preparation to insure the proper strength. The sodium salts formed with the impurities in the rags during boiling are soluble in water and can be readily washed out after the boiling is finished. Rags cooked with caustic soda are therefore comparatively free from deleterious impurities.

Lime is a comparatively weak alkali and only a small amount is in solution and, therefore, in active form at a given time. (See Technologic Paper No. 329, p. 93.) There is therefore less danger of lowering the fiber strength by excessive chemical attack. Owing to the fact that lime salts precipitate on the fibers when cold, the compounds formed are practically insoluble and there is greater difficulty in thoroughly freeing the rags from the impurities in the washing process.

The results confirm the statement in the earlier publication that gradual application of roll pressure in the beating process was the chief contributing factor in the greater strength of the papers made at the bureau. It was again demonstrated that with the same raw materials a suitable change in beating practice doubled the folding strength of the finished paper.

The greatest strength was obtained with the 75 per cent linen and 25 per cent cotton composition, but the 50:50 combination of these fibers produced a strong sheet, of somewhat better printing quality. The folding endurance of the 50 per cent linen, 50 per cent cotton papers was, nevertheless, well above the contract specification for currency paper (3,500 double folds), and the use of that fiber com- 
position is worth consideration by commercial manufacturers. It should be remembered, however, that fiber loss in cooking is greater for linen than for cotton and that paper made from these materials cooked together will therefore have a relatively larger percentage of cotton than the boiler furnish.

Because of differences in inherent physical characteristics, linen develops better cohesive properties in the beating process than cotton, and the surface of the paper made from it is therefore firmer and freer from fuzz. An all-linen composition, however, gives too hard a paper for currency use.

The folding strength is less uniform in the two directions of the sheet for cotton stock, and the tensile strength is lower for papers containing cotton. These conditions do not necessarily indicate lower fiber strength of cotton than linen, but may be due to the difference in the cohesive properties of the fibers. The higher tearing strength of the papers containing large proportions of cotton is also explained by the inherent physical nature of the fiber, twisted fiber having higher tear resistance than straight.

Surface sizing is considered essential for satisfactory printing results by the wet intaglio process. The excellence of the printing on the finished currency is the main hindrance to effective counterfeiting. Uniform wetting quality of the paper is necessary to facilitate production. Experimental sizing and printing tests indicated that 4 per cent concentration of glue in the sizing bath, one-fourth of 1 per cent formaldehyde as glue preservative, and $130^{\circ} \mathrm{F}$. as temperature of the bath were the most satisfactory sizing conditions for currency paper.

Commercial mills following the procedure used at the bureau in the currency tests obtained papers of similar quality. Likewise, paper made at the bureau from beaten stuff prepared in a commercial mill gave results duplicating those obtained on the commercial machine. The comparative data show the applicability of the experimental tests to commercial production.

As a result of the investigation, the cooperating commercial mills are now producing a paper similar to that developed at the bureau. The improvement made is doubtless reflected in the quality of other rag-content papers also. It is believed that the test data will be of value in the general technic of paper-making.

Washington, April 3, 1929. 